\title{
SPeed Control of a Permanent Magnet D.C. SERVOMOTOR THROUGH COMPACTRIO 9074
}

\author{
Livinti Petru \\ Vasile Alecsandri” University of Bacau, Street Marasesti 157, Bacau, 600115, Romania
}

\begin{abstract}
This work presents an electric drive system equipped with a permanent magnet D.C. servomotor supplied from a D.C. voltage converter. For designing the speed regulator, the module criterion has been used, namely the Kessler variant. In the LabVIEW graphic programming environment an application has been conceived for real time control of the permanent magnet D.C. servomotor speed (rpm). For implementing the application in real time, a P.C. has been used, as well as a data acquisition board CompactRIO 9074 produced by National Instruments - U.S.A.
\end{abstract}

Keywords: computerized system; permanent magnet D.C. servomotor; data acquisition board CompactRIO
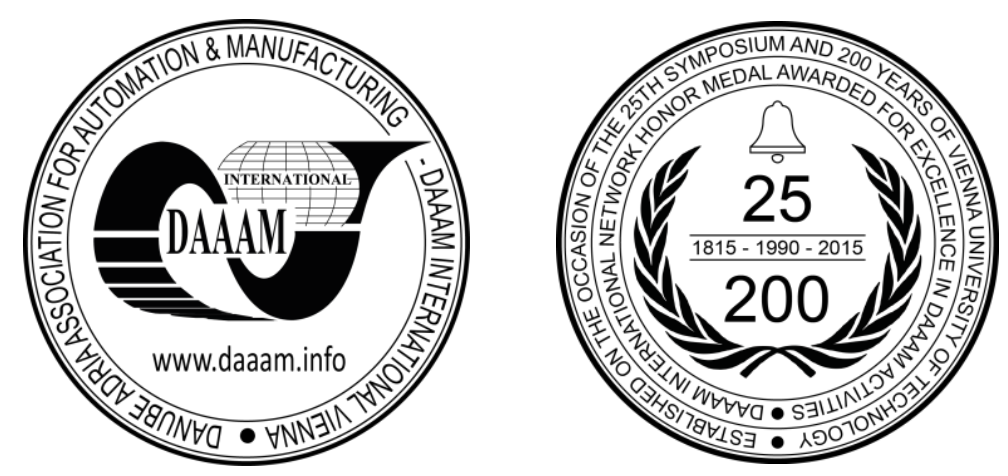

This Publication has to be referred as: Livinti, P[etru] (2016). Speed Control of a Permanent Magnet D.C. Servomotor through CompactRIO 9074, Proceedings of the 26th DAAAM International Symposium, pp.0156-0165, B. Katalinic (Ed.), Published by DAAAM International, ISBN 978-3-902734-07-5, ISSN 1726-9679, Vienna, Austria DOI:10.2507/26th.daaam.proceedings.022 


\section{Introduction}

This work presents an electric drive system equipped with a permanent magnet and disk rotor D.C. servomotor from the industrial production, model SRD 1000 manufactured in Romania. Complex and high performance applications may be achieved in the LabVIEW graphic programming environment at relatively low costs. The LabVIEW programming environment offers, through its libraries, all needed components for performing graphic interfaces, simple and easy to use, [1], [2], [3]. By considering the previous arguments, it may be certainly said that the LabVIEW environment, through its facilities, represents a feasible solution for controlling the speed of the electric drive systems equipped with permanent magnet D.C. servomotors, [4], [5], [6]

\section{Structure of the electric drive system}

$\wedge \quad$ The block diagram of the electric drive system controlled by means of an application performed in the LabVIEW graphic programming environment is shown at Fig. 1. The block diagram shown at Fig. 1 uses the following notations: VTC - D.C. voltage variation unit; SMCC-D.C. servomotor with disk rotor; $T_{n}-\mathrm{rpm}$ encoder; F - filter; CNA - numeric/analogue converter; CAN -analogue/numeric converter; - output angular speed on the servomotor shaft; - control size of the voltage converter supplied by the speed regulator; - imposed reference; reaction size; - error; RNV - speed numerical regulator. Based on the structure shown at Fig. 1, a stand for adjusting the speed (rpm) of permanent magnet D.C. servomotors has been built at the University "Vasile Alecsandri" in Bacău, as shown at Fig. 2.

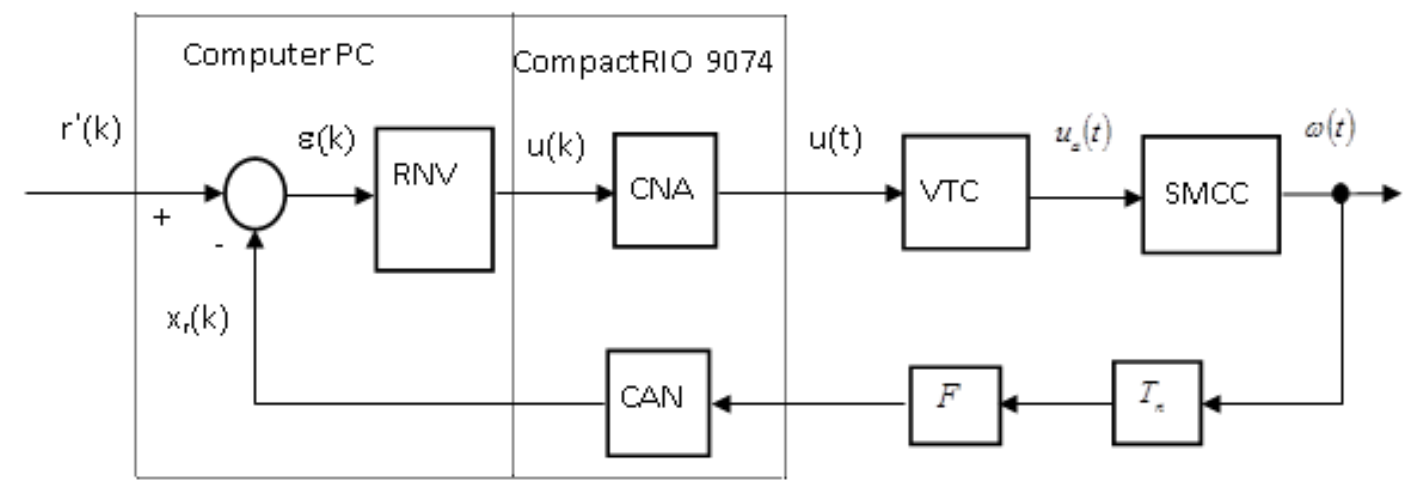

Fig. 1. Structure of the speed (rpm) adjusting system

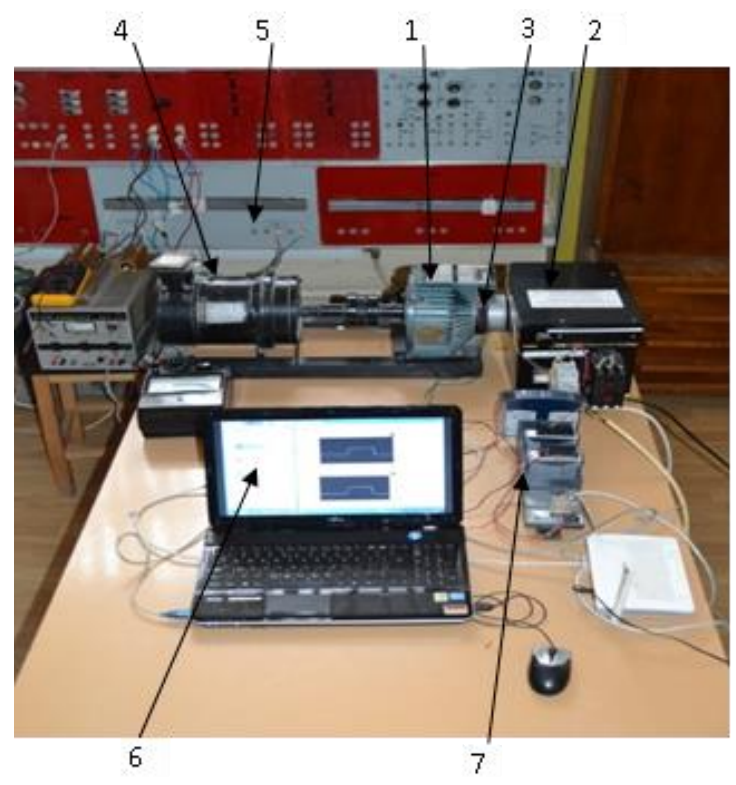

Fig. 2. Experimental stand

The equipment used for building this stand has the following characteristics: 1- Permanent magnet D.C. servomotor model SRD 1000: rated power $P_{n}=1000 \mathrm{~W}$; rated voltage $U_{n}=82 \mathrm{~V}$ D.C.; rated current $I_{n}=15$ A; rated $\mathrm{rpm} n_{n}=3000 \mathrm{rev} / \mathrm{min}$; rated torque $m=320 \mathrm{~N} \cdot \mathrm{cm} ; R_{a}=0.5 \Omega ; L_{a}=0.47 ;$ inertia moment $J_{1}=1 \cdot 10^{-3} \mathrm{kgm} ; 2$ 
- D.C. voltage variation unit built at the Electric Machinery Laboratory: supply voltage: 220 V.A.C.; rated power $P_{n}=1.3 \mathrm{KW}$; output voltage: 90 V.D.C.; reference signal $(0 \div 5)$ V.D.C.; maximum value of the output current: 15 A; 3 - D.C. tacho-generator model TG 3 of output voltage $(0 \div 60)$ V.D.C. for rpm ranging within $(0 \div 3000) \mathrm{rpm} ; 4-$ D.C. generator with separate excitation is of type CI $90 \mathrm{FR}$ : rated power $P_{n}=0.720 \mathrm{~kW}$, rated voltage $U_{n}=110$ V.D.C., rated current $I_{n}=11 \mathrm{~A}$, rated $\mathrm{rpm} n_{g n}=1550 \mathrm{rpm}$, inertia moment $J_{2}=0.5 \cdot 10^{-3} \mathrm{kgm}^{2} ; \quad 5-$ The load resistance of the D.C. generator is composed of a fixed power resistor $R_{1}=7.4 \Omega$ and a variable power resistor of maximum value $R_{2}=95 \Omega ; 6$ - Portable computer of Fujitsu type: Processor Intel(R), Core(TM) i5-2450 M, 2,5 GHz, RAM memory 6GB, 32 bit Operating System; 7 - The data acquisition board CompactRIO 9074 is produced by National Instruments U.S.A.: a) Central unit module NI cRIO-9074: - monitoring system $400 \mathrm{MHz}$ industrial real time processor for control, data logging, and analysis; 2M gate, 8-slot FPGA chassis for custom I/O timing, control, and processing; - Two 10/100 BASE-T Ethernet ports; RS 232 serial port for connection to peripherals; single 19 to 30 VDC power supply input; b) Module NI PS-15 Power Supply, 24 VDC, 5 A, 100- 120/200-240 VAC Input. c) analogue/numeric input module NI-9215: 4 simultaneously sampled analog inputs, $100 \mathrm{kS} / \mathrm{s}$; -16- bit resolution; - Hot-swappable operation; - 40 to $70{ }^{\circ} \mathrm{C}$ operating range; -NIST-traceable calibration. d) Numeric/analog output module, NI-9263: 4 simultaneously updated analog outputs, 100 kS/s; - 16- bit resolution; - Hotswappable operation; - 40 to $70^{\circ} \mathrm{C}$ operating range; - NIST-traceable calibration.

\section{Determining the mathematical model of the permanent magnet D.C. servomotor}

The case of a permanent magnet D.C. servomotor is considered. The running equations of the D.C. servomotor are [7]:

$$
\begin{aligned}
& u_{a}=R_{a} i_{a}+L_{a} \frac{d i_{a}}{d t}+k \cdot \Omega \\
& m=k \cdot i_{a} \\
& J \frac{d \Omega}{d t}=m-m_{r}-m_{f}
\end{aligned}
$$

where: $\quad u_{a}$ - armature supply voltage; $R_{a}, L_{a}$ - armature resistance and inductivity, respectively; $i_{a}$ - current in the armature circuit; $k$ - motor torque constant; $m$ - electromagnetic torque developed by the motor; $m_{r}$ - useful resistant torque produced by load (working machine driven by the motor) that means the perturbing size of the system; $m_{f}$ friction torque; $\mathbf{J}$ - inertia moment of the masses at rotation motion; $\Omega$ - armature angular speed. From the equation system (1), by eliminating the current in the armature circuit $i_{a}$ and applying the Laplace transformation [7], the following transfer function will result:

$$
\Omega(s)=H_{m}(s) \cdot u_{a}(s)-H_{T}(s) \cdot\left[m_{r}(s)+m_{f}(s)\right\rfloor
$$

where:

$$
H_{m}(s)=\frac{k}{s J\left(R_{a}+s L_{a}\right)+k^{2}}
$$

and

$$
H_{T}(s)=\frac{R_{a}+s L_{a}}{s J\left(R_{a}+s L_{a}\right)+k^{2}}
$$

The analysis of the drive system with D.C. servomotor is performed considering $m_{r}$ (useful resistant torque produced by load) constant and the friction torque $m_{f}$ neglected. The transfer function will be [8]:

$$
H_{m}(s)=\left.\frac{\Omega(s)}{u_{a}(s)}\right|_{m_{r}(s)=0}=\frac{k}{s J\left(R_{a}+s L_{a}\right)+k^{2}}
$$


The following constant values are defined, [9]: $\tau_{e}=\frac{L_{a}}{R_{a}}-$ time electromagnetic constant, [9]; $\tau_{m}=\frac{R_{a} J}{k^{2}}-$ time electromechanical constant of the electric drive system. Since $\tau_{m} \gg \tau_{e}$, the transfer function may be expressed by the relation:

$H_{m}(s)=\left.\frac{\Omega(s)}{u_{a}(s)}\right|_{m_{r}(s)=0}=\frac{1}{k\left(1+s \tau_{m}\right) \cdot\left(1+s \tau_{e}\right)}$

\section{Mathematical model of the fixed part of the RPM adjusting loop}

The transfer function for the fixed part $H_{F}(s)$ of the rpm adjustment loop shown at Fig. 2 is given by the relation:

$$
H_{F}(s)=H_{m}(s) \cdot H_{V T C}(s) \cdot H_{T g}(s) \cdot H_{f}(s)
$$

where: $H_{m}(s)$ - transfer function of the permanent magnet D.C. servomotor; $H_{V T C}(s)$ - transfer function of the D.C. voltage variation unit; $H_{T g}(s)$ - transfer function of the rpm encoder; $H_{f}(s)$ - transfer function of the filter circuit. The transfer function parameters of the D.C. servomotor are determined through the relation (6). The inertia moment J of the electric drive system is given by the sum of the inertia moments of the D.C. servomotor and load (the D.C. generator coupled on the same shaft with the D.C. servomotor). From the catalog data, the inertia moment of the D.C. servomotor is $J_{1}=1 \cdot 10^{-3} \mathrm{~kg} \cdot \mathrm{m}^{2}$ and the load inertia moment is $J_{2}=0.5 \cdot 10^{-3} \mathrm{~kg} \cdot \mathrm{m}^{2}$. It will result:

$$
J=J_{1}+J_{2}=1 \cdot 10^{-3}+0.5 \cdot 10^{-3}=1.5 \cdot 10^{-3} \mathrm{~kg} \cdot \mathrm{m}^{2}
$$

The torque constant $k$ of the servomotor is:

$k=\frac{m}{i_{a}}=\frac{3.2}{15}=0.21 \mathrm{~N} \cdot \mathrm{m} / \mathrm{A}$

The time electromechanical constant of the drive system will result:

$\tau_{m}=\frac{R_{a} J}{k^{2}}=\frac{0.5 \cdot 1.5 \cdot 10^{-3}}{0.21^{2}}=0.017 \mathrm{~s}$

The time electromagnetic constant $\tau_{e}$ of the permanent magnet D.C. servomotor is:

$\tau_{e}=\frac{L_{a}}{R_{a}}=\frac{0.47 \cdot 10^{-3}}{0.5}=0.00094 \mathrm{~s}$.

The D.C. servomotor transfer function given by the relation (6) may be expressed under the following form:

$H_{m}(s)=\frac{1 / k}{\left(1+s \tau_{m}\right) \cdot\left(1+s \tau_{e}\right)}=\frac{4.76}{(1+0.017 s) \cdot(1+0.00094 s)}$

The tacho-generator and voltage variation unit are considered to behave as elements free of inertia, having constant transfer functions $k_{T g}$ and $k_{d}$ respectively. For the voltage variation unit the constant $k_{d}$ is determined through the relation:

$k_{d}=\frac{U_{\text {iesire }}}{U_{\text {int rare }}}=\frac{90}{5}=18$

The voltage signal on the tacho-generator output is applied to the input of a resistive divider with the voltage ratio: $k_{u}=\frac{1}{15}$. Thus, the output voltage from the resistive divider will be: 
$U_{d i v}=k_{u} \cdot U_{T g}=\frac{60}{15}=4$ V D.C.

The tacho-generator constant $k_{T g}$ is determined through the relation:

$$
k_{T g .1}=\frac{4}{3000} \cdot \frac{60}{2 \pi}=0.013 \frac{\mathrm{V}}{\mathrm{rad} / \mathrm{s}}
$$

From the relation (7) it will result that a servomotor may theoretically reach a maximum speed when controlled through the voltage $\mathrm{U}$, given by the relation:

$\Omega_{\text {max }}=\frac{U}{k}=\frac{90}{0.21}=428.57 \mathrm{rad} / \mathrm{s}$

In practice, this limit will never be reached because there will always exist a friction torque, different from zero. The tacho-generator with the constant $k_{T g .1}=0.013 \mathrm{~V} / \mathrm{rad} / \mathrm{s}$ will supply a voltage rate proportional to the motor rpm, namely:

$U_{T g}=k_{T g .1} \cdot \Omega_{\text {max }}=0.013 \cdot 428.57=5.57 \mathrm{~V}$

Since this signal exceeds the input range to the regulator, of $(0 \div 4)$ V.D.C., it must be attenuated through the division factor given by the relation:

$k_{\Omega}=\frac{U_{r e f}}{U_{T g}}=\frac{4}{5.57}=0.72$

The tacho-generator constant will result, given by the relation:

$k_{T g}=k_{\Omega} \cdot k_{T g .1}=0.72 \cdot 0.013=0.0094$

For reducing the influence of the tacho-generator voltage pulsations, as well as of the transient process in the motor on the behaviour of the rpm loop, a filter $\mathrm{F}$ will be inserted that has the following transfer function:

$$
H_{f}(s)=\frac{1}{T_{f} \cdot s+1}
$$

The time constant $T_{f}=0,008 \mathrm{~s}$ will be selected for the filter. For designing the filter it is considered:

$T_{f}=R C$

where: $\mathrm{R}$ - resistance, $\mathrm{C}$ - condenser. $C=1 \mu F$ will be selected. It results:

$$
R=\frac{T_{f}}{C}=\frac{0.008}{1 \cdot 10^{-6}}=8 \mathrm{~K} \Omega
$$

The transfer function of the fixed part will become:

$$
\begin{aligned}
& H_{F}(s)=\frac{1 / k \cdot k_{d} \cdot k_{T g}}{\left(1+s \tau_{m}\right) \cdot\left(1+s \tau_{e}\right) \cdot\left(1+T_{f} s\right)}= \\
& =\frac{1 / 0.21 \cdot 18 \cdot 0.0094}{(1+0.017 s) \cdot(1+0.00094 s) \cdot(1+0.008 s)}= \\
& =\frac{0.81}{(1+0.017 s) \cdot(1+0.00094 s) \cdot(1+0.008 s)}
\end{aligned}
$$




\section{Synthesis of the speed regulator}

For the synthesis of the analogue speed regulator of PI type the Kessler variant of the module criterion for rapid processes will be used. This is a criterion that allows optimum tuning of the regulators designed for rapid processes (without idle time, $\tau=0$ ). This criterion assures a good behaviour of automatic adjustment systems at several classes of reference and perturbations. For the transfer function of the fixed part the following notations are used [10]:

$$
k_{e}=0.81 ; T_{1}=0.017 ; T_{\gamma 1}=0.00094 ; T_{\gamma 2}=0.008
$$

The constant $T_{1}$ is the main time constant. $T_{\Sigma}=\sum_{i} T_{y i}$ means the sum of parasite time constants $\left(T_{\dot{\gamma}} \leq(5 \div 10) \cdot T_{1}\right)$.

$$
T_{\Sigma}=\sum_{i} T_{\gamma i}=T_{\gamma 1}+T_{\gamma 2}=0.00094+0.008=0.00894
$$

The transfer function of the fixed part has no pole in origin. For this type of process, the compliance with the module criterion conditions requires the choice of a regulator having the transfer function of the form [10], [11]

$$
H_{R V}=\frac{\left(1+\tau_{k} s\right)}{\tau_{i} s}
$$

where $\tau_{k}=T_{1}=\tau_{m} ; \tau_{i}=2 \cdot k_{e} \cdot T_{\Sigma}$. The amplification factor of the regulator will result:

$$
k_{R}=\frac{\tau_{k}}{\tau_{i}}=\frac{\tau_{k}}{2 \cdot k_{e} \cdot T_{\Sigma}}
$$

This criterion assures the system accuracy at a step type input signal i.e.: over-adjustment $\sigma=4.5 \%$ and duration of the transient process, ${ }_{t}=6.73 T_{\Sigma}$. The parameters of the speed regulator may be calculated through the relations:

$$
\begin{aligned}
& \tau_{k}=T_{1}=\tau_{m}=0.017 \\
& \tau_{i}=2 \cdot k_{e} \cdot T_{\Sigma}=2 \cdot 0.81 \cdot 0.00894=14.5 \cdot 10^{-3} \\
& k_{R}=\frac{\tau_{k}}{2 \cdot k_{e} \cdot T_{\Sigma}}=\frac{0.017}{14.5 \cdot 10^{-3}}=1.17
\end{aligned}
$$

The transfer function of the speed regulator given by the relation (16) may be expressed under the form:

$$
H_{R V}=\frac{\left(1+\tau_{k} s\right)}{\tau_{i} s}=\frac{(1+0.017 s)}{14.5 \cdot 10^{-3} s}=1.17+\frac{1}{14.5 \cdot 10^{-3} s}
$$

The integrating constant of the PI speed regulator expressed in minutes is calculated through the relation:

$$
T_{i}=\frac{\tau_{i}}{60}=\frac{14.5 \cdot 10^{-3}}{60}=0.24 \cdot 10^{-3} \mathrm{~min}
$$

\section{Experimental results}

For the real time control of the permanent magnet D.C. servomotor rpm a graphic interface has been built in the LabVIEW programming environment [12]. The graphic interface is composed of two parts. The first part of the graphic interface corresponds to the program Host_livinti_VI.vi. The block diagram of this program is shown at Fig. 3 and its front panel is shown at Fig. 4. 


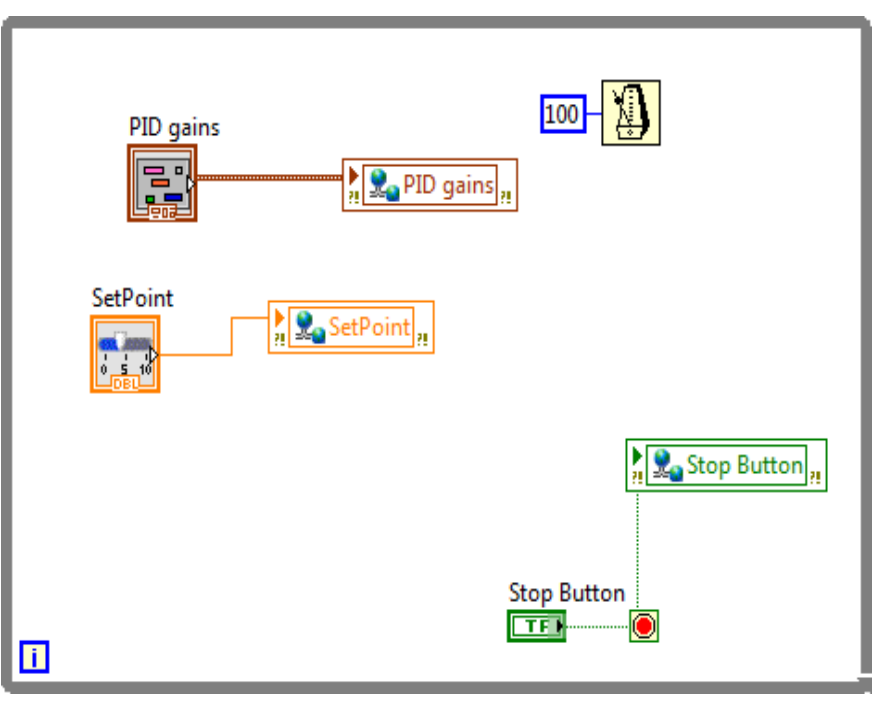

Fig. 3. Block diagram_Host_livinti_VI.vi

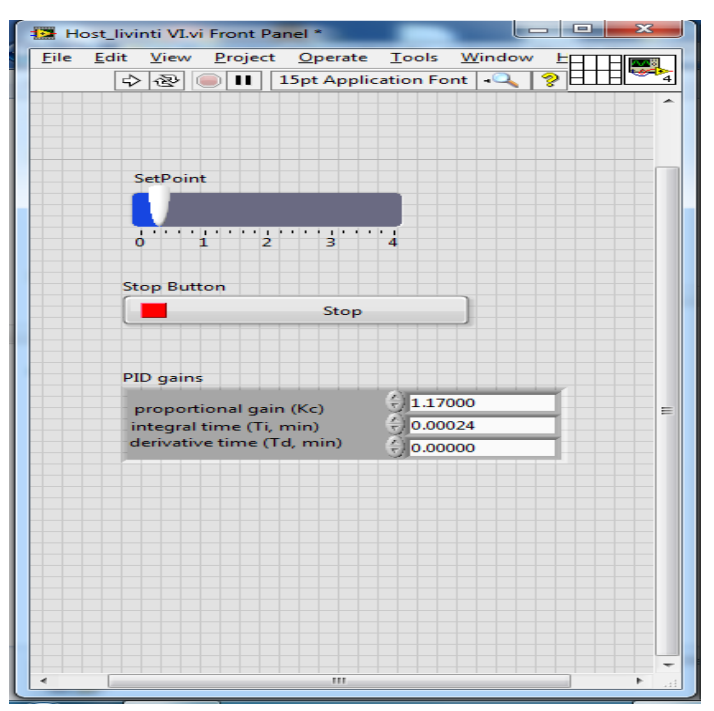

Fig. 4. Front panel - Host_livinti_VI.vi

This program allows setting the parameters of the PI type speed regulator and modifying the reference value with the help of the SetPoint potentiometer. The second part of the graphic interface corresponds to the program RT_livinti_VI.vi. The block diagram of this program is shown at Fig. 5. The front panel of this program includes an indicating gauge for the reference size and the control size (autopid) and an indicating gauge for the reaction size measured through the tacho-generator (Waveform chart). With the help of this program the algorithm for adjusting the rpm of the permanent magnet D.C. servomotor, of PI type, in real time, is performed. Within this program the acquisition in real time of the reaction size is performed through the channel AI 0 of the analog/numeric input module NI 9215 as well as of the reference signal from the SetPoint potentiometer. The error signal is calculated, that is equal to the difference between the two signals and is processed according to the adjustment algorithm of PI type in the PID block. The output signal of the PI regulator is input to the PID $\Delta U / \Delta t$ limiting block. The output signal of the PID $\Delta U / \Delta t$ limiting block of the regulator will be the control size that will be transmitted to the D.C. voltage variation unit through the numeric/analog output channel AO1 of the module NI 9263. The connection between the two programs will be done by means of the variables of type Shared variable Network: SetPoint, PID Gains and STOP Button.

\subsection{Experimental results on the idle running of the permanent magnet D.C. servomotor for three different values of} the reference size

After starting the permanent magnet D.C. servomotor, three successive values of the reference size will be controlled through the SetPoint potentiometer, as follows: 1.1 V.D.C.; 3.3 V.D.C. and 1.8 V.D.C. The variations being obtained on the front panel of the program RT_livinti.vi for the control and reference sizes are shown at Fig. 6. The variation obtained on the front panel of the program $R T \_$livinti.vi for the reaction size (variation of the signal supplied by tacho-generator) is shown at Fig. 7. For the value of the reference voltage applied to the D.C. voltage variation unit, of 3.4 V.D.C., from the diagram shown at Fig. 7, the following values of the reaction size have resulted: the maximum value $y_{\max 1}=3.65$ and the stationary value $y_{s 1}=3.52$. The value of the over-adjustment $\sigma_{01}$ of the adjustment system is determined by the relation:

$\sigma_{01}=\frac{y_{\max 1}-y_{s 1}}{y_{s 1}}=\frac{3.65-3.52}{3.52}=0.037=3.7 \%$

From Fig.7 it results that the duration of the transient duty $\left(t_{t}\right)$ of the time response of the speed adjustment loop upon the modification of the reference value is equal to $0,058 \mathrm{~s}$.

\subsection{Experimental results on the running at load of the permanent magnet D.C. servomotor for two different values of the reference size}

After starting the permanent magnet D.C. servomotor, two successive values of the reference size will be controlled through the SetPoint potentiometer, as follows: 2.6 V D.C. and 3.3 V D.C. In approximately $500 \mathrm{~ms}$ after the idle start - up, the load resistor will be connected to the terminals of the D.C. generator coupled to the same shaft as the D.C. servomotor, for each determining apart. The variations obtained on the front panel of the program 
RT_livinti.vi for the reaction size are shown at Fig. 8 and Fig. 9. For the value of the reference voltage applied to the D.C. voltage variation unit, of 2.6 V.D.C., from the diagram shown at Fig. 8 have resulted the following values of the reaction size: the maximum value $y_{\max 2}=2.6$ and the stationary value $y_{s 2}=2.55$. The value of the over-adjustment $\sigma_{02}$ of the adjustment system is determined by the relation:

$\sigma_{02}=\frac{y_{\max 2}-y_{s 2}}{y_{s 2}}=\frac{2.6-2.55}{2.55}=0.019=1.9 \%$

For the value of the reference voltage applied to the D.C. voltage variation unit, of 3.3 V.D.C., from the diagram shown at Fig. 9 have result the following values of the reaction size: the maximum value $y_{\max 3}=3.3$ and the

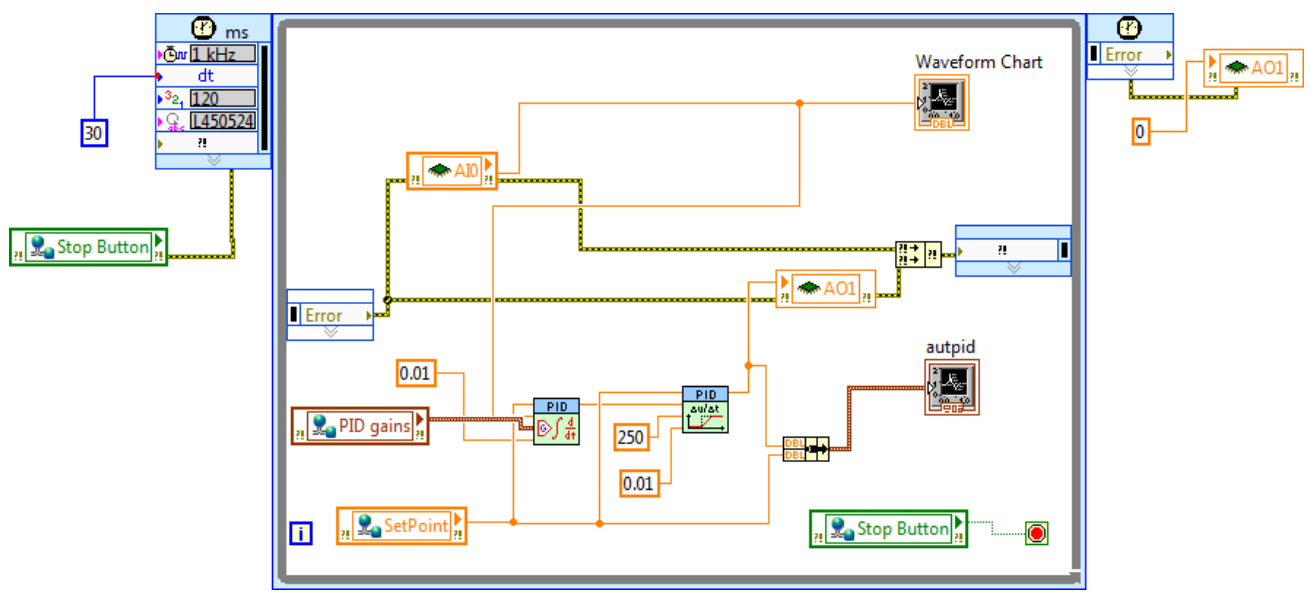

Fig. 5. Block diagram of the program RT_livinti_VI.vi

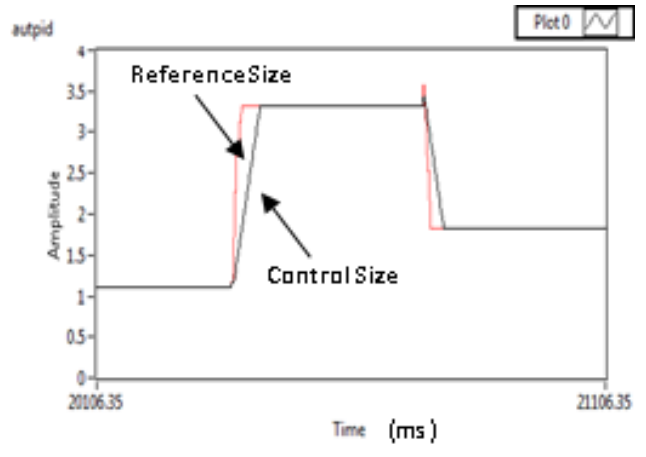

Fig. 6. Variation of Reference and control sizes

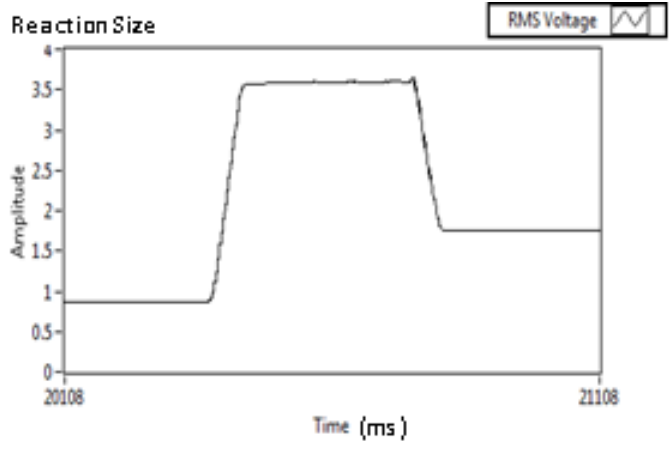

Fig. 7. Variation of the reaction size at idle running

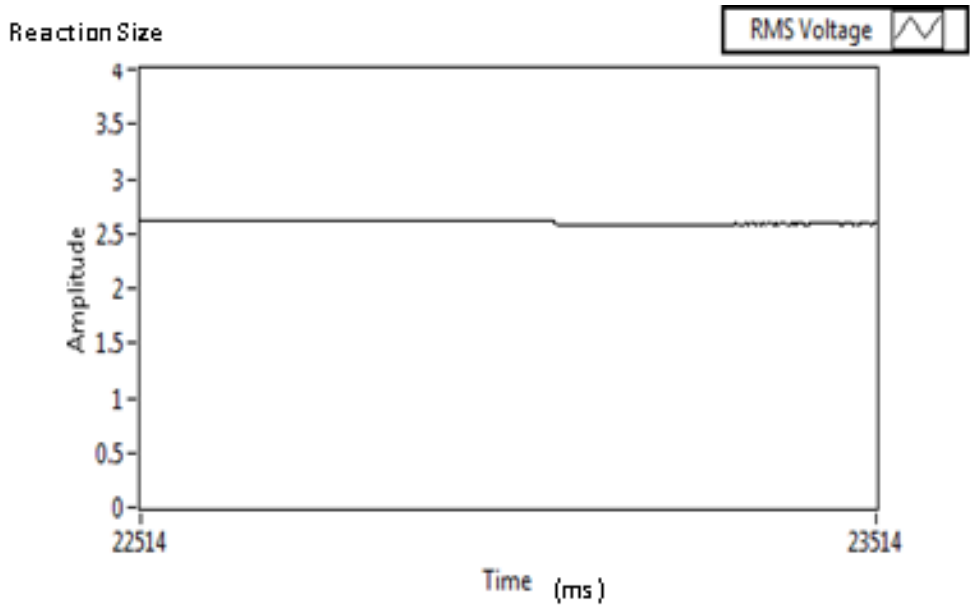

Fig. 8. Variation of the reaction size at load running for $\mathrm{U}_{\text {ref }}=2.6 \mathrm{~V}$ D.C 
stationary value $y_{s 2}=3.25$. The value of the over-adjustment $\sigma_{03}$ of the adjustment system is determined by the relation: The value of the over-adjustment $\sigma_{03}$ of the adjustment system is determined by the relation:

$$
\sigma_{03}=\frac{y_{\max 3}-y_{s 3}}{y_{s 3}}=\frac{3.3-3.25}{3.25}=0.015=1.5 \%
$$

From the analysis of the graphics it results that the control system of the permanent magnet D.C. servomotor speed achieves the required performances.

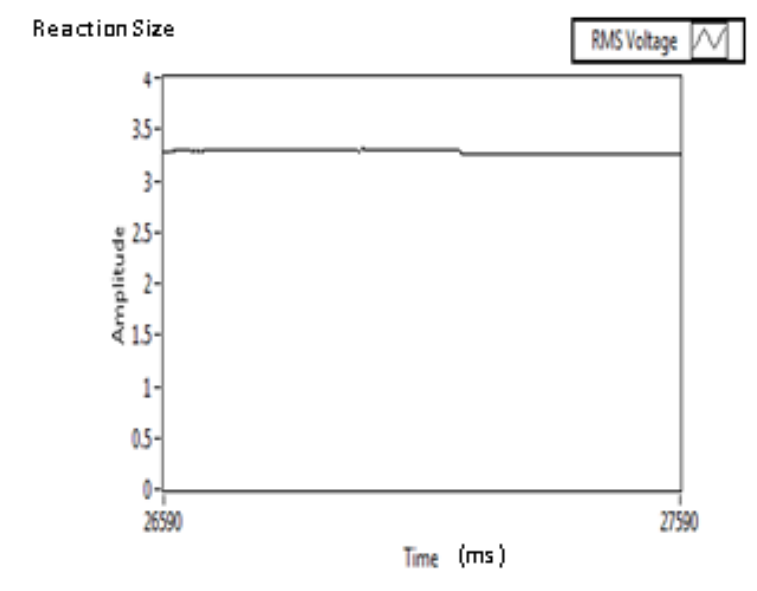

Fig. 9. Variation of the reaction size at load running for $\mathrm{U}_{\text {ref }}=3.3 \mathrm{~V}$ D.C

\section{Conclusions}

This work presents a system of electrical drive consisting of a D.C. servomotor with permanent magnets, for which a speed regulator of PI (proportional-derivative) type has been implemented in real time, by using the LabVIEW programming environment and the data acquisition and control board CompactRIO 9074. With the help of an experimental stand the speed (rpm) rates variations in real time of the D.C. servomotor have been determined for various values of the reference size, both at idle running and load running. From the analysis of the results (over adjustment $\sigma=3.7 \%$ and transient duty duration $t_{t}=0.058 \mathrm{~s}$ ) it results that the speed regulator that has been implemented assures for the response in real time of the speed adjustment loop better performances compared to the case of using speed regulators of industrial type. The forthcoming activity will focus on the design and implementation of a fuzzy regulator in the LabVIEW programming environment for the speed control of the D.C. servomotor with permanent magnets.

\section{References}

[1] Bhushana Thakur, Prof. Sujata Kulkarni:’Hardware Implimentation of FPGA based PID Controller", International Journal of Engineering Research \& Technology (IJERT), ISSN: 2278-0181, Vol. 4 Issue 02, February-2015, pp. $872-875$

[2] Vipul B. Patel, Virendra singh and Ravi H.Acharya, -Design of FPGA-based All Digital PID Controller for Dynamic Systems\|, International Journal of Advanced Research in Electrical, Electronics and Instrumentation Engineering, Vol. 1, Issue 2, pp 64-72, August 2012.

[3] Ivneet Kaur Kaler and Ritesh Diwan, - Study of FPGA based PID controllersll, International Journal of Advanced Research in Electronics and Communication Engineering (IJARECE), Volume 2, Issue 8, pp 708-712, August 2013.

[4] Ahmed Telba: "Motor Speed Control Using FPGA", Proceedings of the World Congress on Engineering 2014 Vol I, WCE 2014, July 2 - 4, 2014, London, U.K., ISSN: 2078-0958 (Print); ISSN: 2078-0966 (Online).

[5] Pratap S Vikhe, Neelam Punjabi, Chandrakant B Kadu: "DC Motor Speed Control Using PID Controller In Lab View", International Journal of Innovative Science and Modern Engineering (IJISME) ISSN: 2319-6386, Volume3 Issue-3, February 2015, pp. 38-41.

[6] Prashant Kumar, Ravi Mishra: "Implementation of FPGA Based PID Controller for DC Motor Speed Control System", International Journal of Engineering Research and Applications (IJERA) ISSN: 2248-9622, Vol. 3, Issue 4, Jul-Aug 2013, pp.2268-2272.

[7] Salim, Jyoti Ohri, Naveen: Speed Control of DC Motor using Fuzzy Logic based on LabVIEW, International Journal of Scientific and Research Publications, Volume 3, Issue 6, June 2013, ISSN 2250-3153, www.ijsrp.org. 
[8] V M Venkateswara Rao: Performance Analysis Of Speed Control Of Dc Motor Using P, PI, PD And PID Controllers, International Journal of Engineering Research \& Technology (IJERT) Vol. 2 Issue 5, May - 2013 ISSN: 2278-0181 www.ijert.org, pp. 60-66.

[9] Saal C., Szabo W.: Electrical Drive Systems. Determining the Running Parameters (Sisteme de actionare electrica. Determinarea parametrilor de functionare) Editura Tehnica Bucuresti, 1981.

[10] Dumitrache I., s.a.: Electronic Automations (Automatizari electronice) Editura Didactica si Pedagogica Bucuresti, 1993

[11] Mary Jermila M, Anju Iqubal, Soumya Raj. L: Pid Auto Tuning Using Relay Feedback, International Journal of Engineering Research \& Technology (IJERT) Vol. 2 Issue 4, April - 2013, ISSN: 2278-0181, pp. 1170-1175.

[12] ****program LabVIEW 2013 Trial. 